\title{
Acute pancreatitis in a patient with COVID-19: a case report
}

\author{
Chiranjeevi Gadiparthi ${ }^{1}$, Sonmoon Mohapatra ${ }^{1}$, Sowjanya Kanna ${ }^{2}$, Vinit Vykuntam ${ }^{3}$, William Chen ${ }^{1}$ \\ ${ }^{1}$ Department of Gastroenterology and Hepatology, Saint Peter's University Hospital-Rutgers Robert Wood Johnson School of Medicine, New \\ Brunswick, NJ, USA; ${ }^{2}$ Department of Gastroenterology and Hepatology, Allegheny Health Network, Pittsburgh, PA, USA; ${ }^{3}$ University of \\ Cambridge School of Clinical Medicine, Cambridge, UK \\ Correspondence to: Chiranjeevi Gadiparthi, MD, MPH. Fellow, Department of Gastroenterology and Hepatology, Saint Peter's University Hospital- \\ Rutgers Robert Wood Johnson School of Medicine, New Brunswick, NJ 08901, USA. Email: chirudoc@yahoo.com.
}

\begin{abstract}
The global pandemic of coronavirus disease-2019 (COVID-19) caused by severe acute respiratory syndrome coronavirus $2(\mathrm{SARS}-\mathrm{CoV}-2)$ is predominantly a respiratory illness, but gastrointestinal (GI) manifestations of variable severity have been reported. In patients with COVID-19 pneumonia, observational studies have demonstrated the elevation of pancreatic enzymes as surrogate markers for pancreatic injury without evidence of acute pancreatitis (AP). We report a case of AP in a patient with COVID-19 with SARS-CoV-2 as possible etiological agent with imaging evidence of pancreatitis. We hypothesize a causal relationship of SARS-CoV-2 in this patient with an otherwise unexplained presentation of AP after excluding the common causes. We postulate that AP in COVID-19 could be related to the abundant expression of angiotensin converting enzyme 2 (ACE 2) receptors in the pancreas which serve as viral entry binding receptors for SARS-CoV-2 or due to direct viral involvement of the pancreas. Although there seems to be an association between diabetes and AP, the available data regarding the etiological role of diabetes in causing AP is very limited. We also propose that imaging studies such as computerized tomography (CT) scan of the abdomen should be considered in the diagnosis of AP in patients with COVID-19 infection to exclude the false positive amylase and lipase.
\end{abstract}

Keywords: Acute pancreatitis (AP); coronavirus disease-2019 (COVID-19); severe acute respiratory syndrome coronavirus 2 (SARS-CoV-2); structural damage; case report

Received: 28 May 2020; Accepted: 15 December 2020; Published: 25 October 2021.

doi: $10.21037 /$ tgh-20-234

View this article at: http://dx.doi.org/10.21037/tgh-20-234

\section{Introduction}

Gastrointestinal (GI) manifestations of coronavirus disease-2019 (COVID-19) have been widely recognized, and they include ageusia, anorexia, nausea and vomiting, abdominal pain, diarrhea and elevated liver enzymes $(1,2)$. The full clinical spectrum of this emerging disease, especially the involvement of the pancreas and other GI organs is still being studied and several aspects remain unknown. Earlier in the pandemic, there were some reports suggestive of pancreatic injury in patients with COVID-19 with indirect evidence of abnormal biochemical tests (elevated amylase and lipase) $(3,4)$. While elevated amylase and lipase are suggestive of acute pancreatitis (AP), such elevations can occur in other conditions unrelated to AP raising the questions about accuracy of the diagnosis and over reporting of AP in these reports. Here, we report a case of AP with evidence of structural damage to the pancreas (imaging evidence) in a COVID-19 patient in addition to biochemical injury and without other known etiology of AP.

We present the following article in accordance with the CARE reporting checklist (available at http://dx.doi. org/10.21037/tgh-20-234).

\section{Case presentation}

A 74-year-old Caucasian woman with a medical history of type 2 diabetes mellitus (T2DM) and prior cholecystectomy 


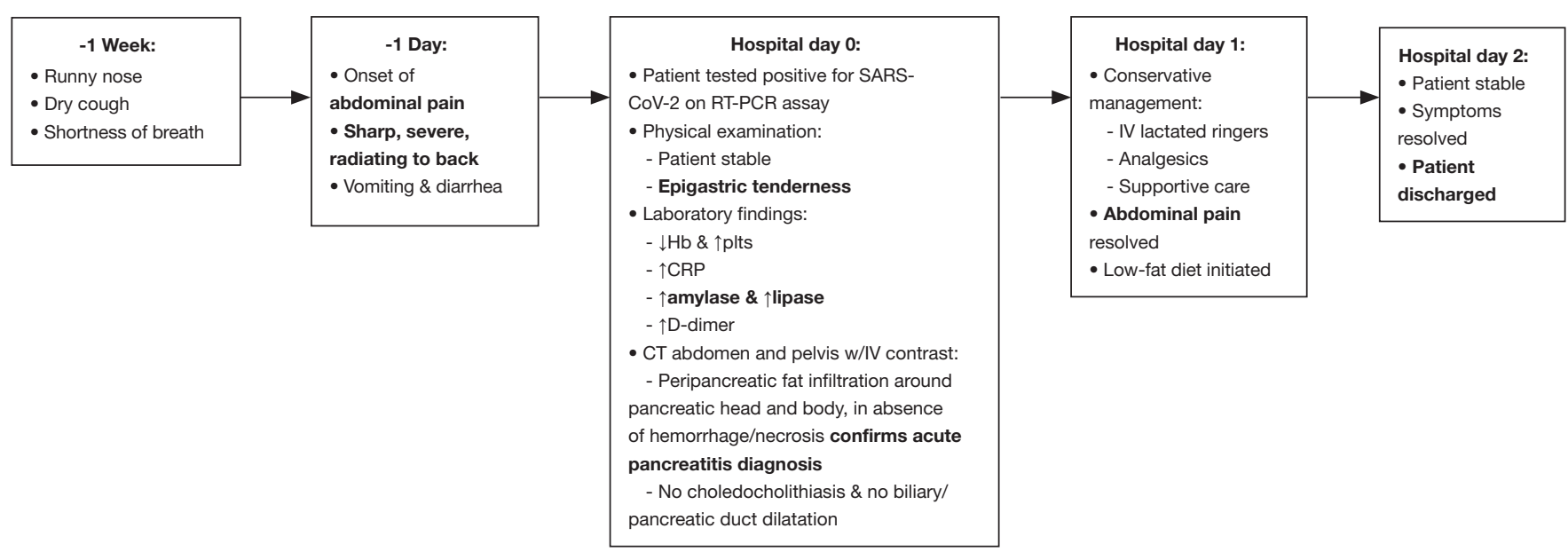

Figure 1 Case-AP in COVID-19 infection timeline. AP, acute pancreatitis; COVID-19, coronavirus disease-2019.

presented to the hospital with epigastric pain of 1-day duration. She described the pain as sharp, severe, radiating to the back, and associated with episodes of vomiting and diarrhea. She has no prior history of pancreatitis, does not consume alcohol or use recreational drugs. Her home medication regimen includes glimepiride, iron sulfate, aspirin, atorvastatin and esomeprazole. One week prior to the hospitalization, the patient developed symptoms of runny nose, dry cough and shortness of breath. She was tested positive for severe acute respiratory syndrome coronavirus 2 (SARS-CoV-2) on nasopharyngeal swabbased reverse transcriptase-polymerase chain reaction assay (RT-PCR). The timeline of this episode of care is shown in Figure 1.

In the emergency room, she had stable vital signs. Abdominal examination revealed epigastric tenderness. Laboratory tests showed hemoglobin of $8.4 \mathrm{~g} / \mathrm{dL}$, white blood cell count of 8,600 per cu mm, platelet count of 462,000 per cu mm, blood urea nitrogen of $23 \mathrm{mg} / \mathrm{dL}$, creatinine of $0.75 \mathrm{mg} / \mathrm{dL}$, serum calcium $8.2 \mathrm{mg} / \mathrm{dL}$, amylase of 229 (normal, 30-151) U/L, and lipase of 7,550 (normal, 11-82) U/L. Serum glucose level was $112 \mathrm{~g} / \mathrm{dL}$ with normal anion gap and normal serum bicarbonate level. Liver tests showed normal aspartate aminotransferase (AST) of 31 (normal, 14-36) U/L, alanine aminotransferase (ALT) of 24 (normal, 9-52) U/L, alkaline phosphatase of 74 (normal, 53-141) U/L and total bilirubin of $0.4 \mathrm{~g} / \mathrm{dL}$. D-dimer 1,608 (normal less than 211) $\mathrm{ng} / \mathrm{mL}$ and C-reactive protein 34 (normal less than 5) $\mathrm{mg} / \mathrm{L}$ were elevated. The serum triglyceride level was 188 (normal less than 150 ) $\mathrm{mg} / \mathrm{dL}$. Computerized tomography (CT) of the abdomen and pelvis with intravenous contrast demonstrated peripancreatic fat infiltration around the pancreatic head and body without hemorrhage or necrosis confirming the diagnosis of AP (Figure 2). There was no choledocholithiasis, biliary or pancreatic ductal dilatation. The patient was managed conservatively with intravenous lactated ringers, analgesics, and supportive care. On hospital day 1, the patient's abdominal pain resolved, and a low-fat diet was initiated. She was discharged home on hospital day 2 in a stable condition after resolution of her symptoms. All procedures performed in studies involving human participants were in accordance with the ethical standards of the institution and with the Helsinki Declaration (as revised in 2013). Written informed consent was obtained from the patient.

\section{Discussion}

The presence of COVID-19 and AP in our patient could be a mere coincidence. However, in a recent case series of 52 hospitalized patients with COVID-19 pneumonia in a single center in China, $17 \%$ had biochemical evidence of pancreatic injury (elevated amylase and lipase) (4), but structural damage to the pancreas, such as edema, pancreatic necrosis, peripancreatic fat stranding or fluid collection, is not established as imaging studies were not available in this observational study. Thus, authors postulated that pancreatic injury in patients with COVID-19 pneumonia could be due to direct viral involvement of the pancreas or from secondary enzyme abnormalities due to severe systemic illness without substantial pancreatic injury. Furthermore, it is established that certain viral illnesses 

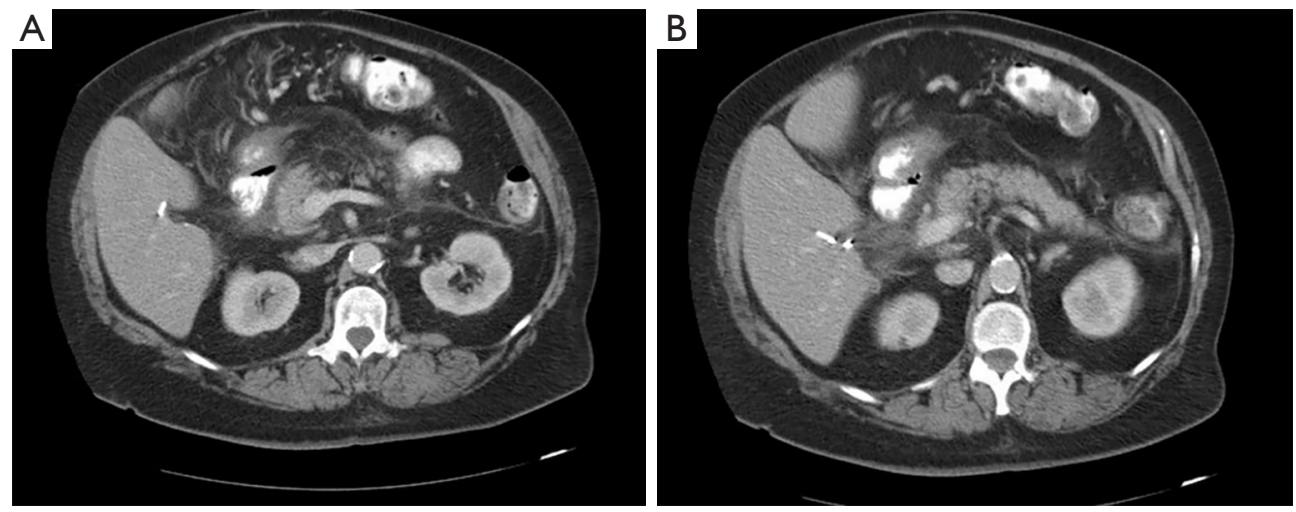

Figure 2 Cross sectional images of contrast enhanced computerized tomography (CT) scan of the abdomen demonstrating peri pancreatic fat stranding (A) and pancreatitis of head and body (B).

such as mumps, coxsackie, Epstein-Barr virus, hepatitis $\mathrm{A}$ and $\mathrm{E}$ are known to cause $\mathrm{AP}(5,6)$. While it is difficult to establish the etiological role of SARS-CoV-2 in AP in our patient, prior studies have demonstrated the expression of angiotensin converting enzyme 2 (ACE 2) in the pancreatic tissue, which also serve as viral entry binding receptors for SARS-CoV-2 $(7,8)$. In a recent case report of a patient with severe COVID-19 pneumonia with ARDS, authors reported AP based on elevated lipase and epigastric pain (3). However, the imaging evidence of AP was absent in this case whereas our patient had clear changes of AP with peripancreatic fat stranding on CT scan. In another case, although authors reported a case of AP in a 24-year-old patient with COVID-19, the possibility of biliary pancreatitis could not be excluded especially in the absence of liver test results (9). Similar cases have been reported recently with COVID-19 as a potential cause of AP, however our case is unique because of our patient had prior cholecystectomy and normal liver enzymes which eliminate possibility of biliary pancreatitis beyond reasonable doubt (10-12).

Some observational studies have reported modest increase in incidence of AP in diabetic patients. In a large population based nested case control study, incidence of AP in T2DM was 54.0 per 100,000 person-years compared to 30.1 in general population (13). The adjusted incidence ratio of AP in this study was 1.77 (95\% CI: 1.46-2.15) in T2DM patients compared to general population. However, after adjusting demographic and lifestyle variables, drug exposure and comorbidities, overall risk of AP in T2DM patients was non-significant (adjusted OR 1.37, 95\% CI: 0.99-1.89). Several reasons for increased AP in T2DM have been postulated such as increasing incidence of obesity perhaps causing increased gallstones or role of some anti-diabetic medications especially glucagon like peptide-1 (GLP-1) analogues. In this study, although there was increased risk of AP with increasing age in overall cohort, there was significant trend towards decreasing association between $\mathrm{AP}$ and diabetes and increasing age $(\mathrm{P}=0.019)$. Association between hyperglycemia, diabetic ketoacidosis (DKA) and AP has been previously reported perhaps due to severe underlying acidemia causing pancreatic acinar cell injury (14). In our elderly diabetic patient, in the absence of DKA, culpable anti-diabetic medications and no clear association between increasing age and diabetes with $\mathrm{AP}$, etiological role of T2DM in AP is highly unlikely.

In conclusion, it is unclear whether AP is a coincidence or consequence of COVID-19 infection. However, in the absence of alternative etiology and due to the aforementioned factors, the role of COVID-19 in causing AP should be considered. AP can be a rare manifestation of pancreatic cancer (15). In certain cases, endoscopic ultrasound may be required to rule out a small tumor, however, in our patient, contrast enhanced CT scan did not show pancreatic cancer. Many aspects of COVID-19 are still being investigated, and larger case series or cohort studies in future may provide insight into the etiological role of SARS-CoV-2 in AP. Nevertheless, it appears that AP could be one among the myriad of GI manifestations caused by COVID-19 albeit less common. Available evidence is meager regarding association of COVID-19 infection, AP and T2DM in the absence of DKA. Nevertheless, factors such as older age and T2DM might have contributed 
to the development of AP in the setting of COVID-19 infection, which is impossible to establish in a single case. However, we recommend high index of suspicion for AP in older COVID-19 patients presenting with abdominal pain especially with underlying T2DM. Due to the non-specific nature of elevated amylase and lipase in the diagnosis of AP, we propose that cross sectional imaging studies should be considered to confirm the diagnosis of AP in patients with COVID-19 infection.

\section{Acknowledgments}

Funding: None.

\section{Footnote}

Reporting Checklist: The authors have completed the CARE reporting checklist. Available at http://dx.doi.org/10.21037/ tgh-20-234

Peer Review File: Available at http://dx.doi.org/10.21037/ tgh-20-234

Conflicts of Interest: All authors have completed the ICMJE uniform disclosure form (available at http://dx.doi. org/10.21037/tgh-20-234). The authors have no conflicts of interest to declare.

Ethical Statement: The authors are accountable for all aspects of the work in ensuring that questions related to the accuracy or integrity of any part of the work are appropriately investigated and resolved. All procedures performed in studies involving human participants were in accordance with the ethical standards of the institution and with the Helsinki Declaration (as revised in 2013). Written informed consent was obtained from the patient.

Open Access Statement: This is an Open Access article distributed in accordance with the Creative Commons Attribution-NonCommercial-NoDerivs 4.0 International License (CC BY-NC-ND 4.0), which permits the noncommercial replication and distribution of the article with the strict proviso that no changes or edits are made and the original work is properly cited (including links to both the formal publication through the relevant DOI and the license). See: https://creativecommons.org/licenses/by-nc-nd/4.0/.

\section{References}

1. Luo S, Zhang X, Xu H. Don't overlook digestive symptoms in patients with 2019 novel coronavirus disease (COVID-19). Clin Gastroenterol Hepatol 2020;18:1636-7.

2. Nobel YR, Phipps M, Zucker J, et al. Gastrointestinal symptoms and coronavirus disease 2019: a casecontrol study from the United States. Gastroenterology 2020;159:373-5.e2.

3. Aloysius MM, Thatti A, Gupta A, et al. COVID-19 presenting as acute pancreatitis. Pancreatology 2020;20:1026-7.

4. Wang F, Wang H, Fan J, et al. Pancreatic injury patterns in patients with coronavirus disease 19 pneumonia. Gastroenterology 2020;159:367-70.

5. Hammami MB, Aboushaar R, Musmar A, et al. EpsteinBarr virus-associated acute pancreatitis. BMJ Case Rep 2019;12:e231744.

6. Sudhamshu KC, Khadka S, Sharma D, et al. Acute pancreatitis in acute viral hepatitis. JNMA J Nepal Med Assoc 2011;51:7-10.

7. Ding Y, He L, Zhang Q, et al. Organ distribution of severe acute respiratory syndrome (SARS) associated coronavirus (SARS-CoV) in SARS patients: implications for pathogenesis and virus transmission pathways. J Pathol 2004;203:622-30.

8. Yang JK, Lin SS, Ji XJ, et al. Binding of SARS coronavirus to its receptor damages islets and causes acute diabetes. Acta Diabetol 2010;47:193-9.

9. Mazrouei SSA, Saeed GA, Al Helali AA. COVID19-associated acute pancreatitis: a rare cause of acute abdomen. Radiol Case Rep 2020;15:1601-3.

10. Bokhari SMMA, Mahmood F. Case report: novel coronavirus-a potential cause of acute pancreatitis? Am J Trop Med Hyg 2020;103:1154-5.

11. Brikman S, Denysova V, Menzal H, et al. Acute pancreatitis in a 61-year-old man with COVID-19. CMAJ 2020;192:E858-9.

12. Rabice SR, Altshuler PC, Bovet C, et al. COVID-19 infection presenting as pancreatitis in a pregnant woman: a case report. Case Rep Womens Health 2020;27:e00228.

13. Gonzalez-Perez A, Schlienger RG, Rodríguez LA. Acute pancreatitis in association with type 2 diabetes and antidiabetic drugs: a population-based cohort study. Diabetes Care 2010;33:2580-5.

14. Nair S, Yadav D, Pitchumoni CS. Association of diabetic 
ketoacidosis and acute pancreatitis: observations in 100 consecutive episodes of DKA. Am J Gastroenterol 2000;95:2795-800.

doi: $10.21037 /$ tgh-20-234

Cite this article as: Gadiparthi C, Mohapatra S, Kanna S, Vykuntam V, Chen W. Acute pancreatitis in a patient with COVID-19: a case report. Transl Gastroenterol Hepatol 2021;6:65.
15. Mujica VR, Barkin JS, Go VL. Acute pancreatitis secondary to pancreatic carcinoma. Study Group Participants. Pancreas 2000;21:329-32. 